\title{
THEORETICAL INVESTIGATION OF STRESSES INDUCED AT BLADE MOUNTING LOCATIONS IN STEAM TURBINE ROTOR SYSTEM
}

\author{
D. KIRAN PRASAD* \\ Department of Mechanical Engineering, Gudlavalleru Engineering College \\ Gudlavalleru- 521356, INDIA \\ E-mail: damarlakiran@gmail.com \\ K.V. RAMANA \\ Department of Mechanical Engineering, K.L. University \\ Vaddeswaram- 522 502, INDIA \\ N. MOHAN RAO \\ Department of Mechanical Engineering, JNT University Kakinada \\ Kakinada-533003, INDIA
}

\begin{abstract}
One of the most common incipient losses of integrity in mechanical structures is the development and propagation of cracks. Especially in rotating members like steam turbine rotors etc. cracks, because of their potential, cause catastrophic failures and are a grave threat to an uninterrupted operation and performance. A crack may propagate from some small imperfections on the surface of the body or inside of the material and it is most likely to appear in correspondence to high stress concentration. Crack propagation path is generally determined by the direction of maximum stress or by the minimum material strength. Hence determination of stresses induced has been the focus of attention for many researchers. In the present work, development of a mathematical model to determine the stresses induced in a rotating disc of varying thickness is studied. This model is applied to a steam turbine rotor disc to determine the induced stresses and radial deflection. The mathematical modeling results are validated with the results obtained using Ansys package. The results of the present study will be useful in diagnosing the location and magnitude of maximum stress induced in the turbine rotor disc and stress intensity factor due to the presence of crack.
\end{abstract}

Key words: rotor disc, radial and tangential stress, steam turbine rotor.

\section{Introduction}

Rotating members called rotors are subjected to different types of structural and thermal loading conditions. Some are directly related with angular velocity or angular acceleration like stresses induced because of centrifugal loads, angular acceleration and gyroscopic couple while the others are independent of rotation like axial thrust. For rotors having turbine blades, brake disks, varying temperature distribution makes the operating conditions even more severe and advancement in technology leads to high speed of rotation. For a given amount of power transmitted, torque can be reduced by lowering the mass of rotating members. Nowadays the operating conditions like high temperatures and thermal gradients and the need to increase the efficiency of components made researchers concentrate more on the stresses induced. Hence the analysis of stresses and strain states in rotors is to be made rigorously to make sure that the components can be designed safely. In addition to that, careful selection of materials, precise testing of finished components for failure, carrying of required non destructive tests on regular basis are also required. All the above means that rotating members are extremely hazardous during operating conditions. A dangerous case involves liberation of ballistic missiles which travel at very high speeds when catastrophic failure of rotors takes

\footnotetext{
* To whom correspondence should be addressed
} 
place. Hence the designer must abide by all the design and safety requirements so that during the actual operating conditions safety is guaranteed.

The mechanisms which cause the blade fatigue and reduction of blade strength are reviewed by Naumann [1]. He also presented the commonly used blade root designs along with the corresponding strengths. Martínez et al. [2] developed a code in FORTRAN about the velocity distribution in the output of stator blades that have flow conditions of wet steam, in order to understand the causes of erosion on the blades of the last stages in the low pressure section of steam turbines. Mazur [3] mode metallographic analyses of cracked blades, natural frequency tests and analyses, blade stress analyses, unit's operation parameters and history of events analyses, fracture mechanics and crack propagation analyses. Shankar [4] performed a 3D finite element analysis (FEA) of a low-pressure (LP) steam turbine bladed disk assembly at a constant speed loading condition. Plesiutschnig [5] analyzed cracks at the root of the third blade row of lowpressure steam turbine blades of different natural frequencies.

In this paper, the issues related to the determination of stresses induced in rotors under steady state conditions subjected to the loads because of rotation, i.e. centrifugal loads, are addressed.

\section{General differential equation for rotating disk subjected to non zero thermal load}

The stresses induced in rotors are three dimensional as they are of complex geometry. Hence in order to obtain the meaningful results, there is a need to have some assumptions so that these assumptions simplify the complexity of the problem and lead to closed form solutions.

One assumption that can be made is the axial symmetry with reference to the geometrical shape and also forces acting. Even though the symmetry related to geometry may not be justified completely, but the effect of disk uniformities can be considered later as localized effect. Another assumption that can be introduced is planes stress, if the dimensions along the axial direction are not too large. This type of rotating member is called a thin disc. With this assumption, the loads acting are considered on the $x y$ plane and the stresses acting along the $\mathrm{z}$ direction can be considered as zero and the stress state is plane .This assumption makes the stress state independent of the axial direction and two coordinates $r$ and $\Theta$ are sufficient to completely describe the problem so that the problem now becomes two dimensional.

The differential Eq.(2.1) which represents a rotating disc subjected to a non zero temperature gradient along the radius is

$$
\frac{d^{2} v}{d r^{2}}+\left(\frac{1}{t} \frac{d t}{d r}+\frac{1}{r}\right) \frac{d v}{d r}+\left(\frac{v}{t r} \frac{d t}{d r}-\frac{1}{r^{2}}\right) v+(1+v) \alpha\left(\frac{d T}{d r}+\frac{T}{t} \frac{d t}{d r}\right)+\left(1-v^{2}\right) \frac{\gamma \omega^{2} r}{\mathrm{E}}=0
$$

where $v$ the displacement, $t$ represents the thickness of the rotating disc, $T$ represents the temperature variation along the radius, $r$ is the radius of the disc from the axis of rotation, $\alpha$ is the thermal coefficient of linear expansion, $\mathrm{E}$ is the Young's modulus of the material and $\omega$ is the angular velocity of rotation.

\section{General formulation of disc with varying thickness}

The disks employed in turbines are generally conical in nature whose thickness varies with radius as $t=t(r)$.

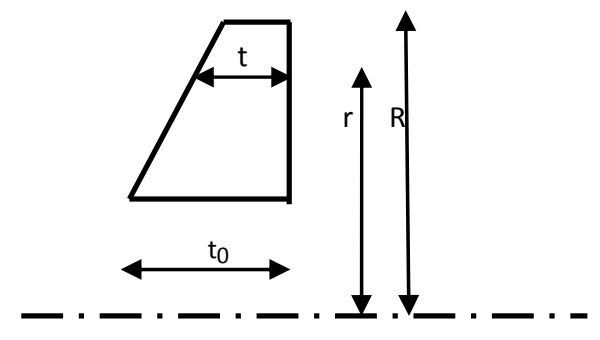

Fig.1. Conical rotating disc of varying thickness. 
For a conical disc as shown in Fig1. $t=t_{0}(1-k)$ where $t$ is a dimensionless variable representing the radius and is given by $k=\frac{r}{R}$, $t_{0}$ is the imaginary disc thickness at the axis.

To derive the standard equation for the displacement field of a disc of varying thickness, the above relation is introduced in the equation along with its derivatives with respect to $t$. Now we obtain the following second order differential equation using the above. The equation is modified as

where

$$
k^{2}(1-k) \frac{d^{2} v}{d t^{2}}+k(1-2 k) \frac{d v}{d t}-(1-k+v k) v=-C R^{3} k^{3}+C R^{3} k^{4}
$$

$$
C=\frac{\left(1-v^{2}\right) \gamma \omega^{2}}{\mathrm{E}}
$$

The solution for the above equation is determined by adding the particular integral of the entire equation to the solution of the associated homogeneous equation.

\section{Combined stress state}

As stated earlier, the displacement and stress state in a varying thickness disc can be obtained by adding the solutions of the associated homogeneous differential equation and corresponding particular integral.

Thus the radial displacement is given by

$$
v=C_{1} q_{1}+C_{2} q_{2}+v_{p}
$$

and the radial and tangential stresses induced are given by

$$
\begin{aligned}
& \sigma_{r}=A a_{r}+B b_{r}+\sigma_{0} g_{r}, \\
& \sigma_{t}=A a_{t}+B b_{t}+\sigma_{0} g_{t} .
\end{aligned}
$$

We will now consider the following four cases to determine the unknown constants $A$ and $B$ while considering these assumptions

$$
\begin{array}{lll}
\left(a_{r}\right)_{k=k_{i}}=U, & \left(a_{r}\right)_{k=k_{e}}=V, & \left(b_{r}\right)_{k=k_{i}}=W, \\
\left(b_{r}\right)_{k=k_{e}}=X, & \left(g_{r}\right)_{k=k_{i}}=Y, \quad\left(g_{r}\right)_{k=k_{e}} Z .
\end{array}
$$

The constants $A$ and $B$ are determined using the conditions of radial stress at the inner or outer radius. For four different cases the above constants are determined and the corresponding equations for radial, tangential stresses and radial displacement are given below.

For a disc loaded at the outer radius

$$
\sigma_{r}\left(\frac{-W a_{r}}{U X-W V}+\frac{-U b_{r}}{U X-W V}\right) \sigma_{r_{e}}+\frac{\left(U^{2} \sigma_{0} Y V W+\sigma_{0} U Y X\right) a_{r}}{U(U X-W V)}+\frac{-U \sigma_{0} Z+\sigma_{0} Y V}{U X-W V} b_{r}+\sigma_{0} g_{r},
$$




$$
\sigma_{t}=\left(\frac{-W a_{t}}{U X-W V}+\frac{-U b_{t}}{U X-W V}\right) \sigma_{r_{e}}+\frac{\left(U^{2} \sigma_{0} Y Z W+\sigma_{0} Y U X\right) a_{t}}{U(U X-W V)}+\frac{-U \sigma_{0} Z+\sigma_{0} Y V}{U X-W V} b_{t}+\sigma_{0} g_{t}
$$

For a disc loaded at the inner radius

$$
\begin{aligned}
& \sigma_{r}=\left(\frac{-X V a_{r}}{V(V W-U X)}+\frac{V b_{r}}{V W-U X}\right) \sigma_{r_{i}}+ \\
& +\frac{\left(\sigma_{0} X(V Y-Z U)-\sigma_{0} Z(V W-U X) a_{r}\right.}{V(V W-U X)}-\frac{\sigma_{0} V Y-\sigma_{0} Z U}{V W-U X} b_{r}+\sigma_{0} g_{r}, \\
& \sigma_{t}=\left(\frac{-V X a_{t}}{V(V W-U X)}+\frac{V^{2} b_{t}}{V(V W-U X)}\right) \sigma_{r_{i}}+\frac{\left(\sigma_{0} X V Y-\sigma_{0} Z V W\right) a_{t}}{V(V W-U X)}+\frac{-V Y \sigma_{0}+\sigma_{0} Z U}{V W-U X} b_{t}+\sigma_{0} g_{t} .
\end{aligned}
$$

For a disc loaded at both the inner and outer radii

$$
\begin{aligned}
& \sigma_{r}=\left(\frac{-X a_{r}}{V(V W-U X)}+\frac{V b_{r}}{V W-U X}\right) \sigma_{r_{i}}+\left(\frac{W a_{r}}{-U X+W V}+\frac{U b_{r}}{U X-W V}\right) \sigma_{r_{e}}+ \\
& +\frac{\left(\sigma_{0} X(V Y-Z U)-\sigma_{0} Z(V W-U X) a_{r}\right.}{V(V W-U X)}-\frac{-\sigma_{0} V Y+\sigma_{0} Z U}{V W-U X} b_{r}+\sigma_{0} g_{r}, \\
& \sigma_{t}=\left(\frac{-X a_{t}}{V(V W-U X)}+\frac{b_{t}}{V(V W-U X)}\right) \sigma_{r_{i}}+\left(\frac{-W a_{t}}{U X-W V}+\frac{-U b_{t}}{U X-W V}\right) \sigma_{r_{e}}+ \\
& +\frac{\left(\sigma_{0} X U Z-\sigma_{0} X V Y-\sigma_{0} Z V W+\sigma_{0} U X Z\right) a_{t}}{V(V W-U X)}+\frac{-U Z \sigma_{0}+\sigma_{0} V Y}{V W-U X} b_{t}+\sigma_{0} g_{t} .
\end{aligned}
$$

For a disc loaded by centrifugal force only

$$
\begin{aligned}
& \sigma_{r}=\frac{\left(-\sigma_{0} X(Y V-U Z)-\sigma_{0} Z(W V-U X)\right) a_{r}}{V(W V-U X)}+\frac{-\sigma_{0} Y V+\sigma_{0} U Z}{-U X+W V} b_{r}+\sigma_{0} g_{r}, \\
& \sigma_{t}=\frac{\left(-\sigma_{0} X(Y V-U Z)-\sigma_{0} Z(W V-U X)\right) a_{t}}{V(W V-U X)}+\frac{-\sigma_{0} Y V+\sigma_{0} U Z}{-U X+W V} b_{t}+\sigma_{0} g_{t} .
\end{aligned}
$$

\section{Case study}

The equations derived above are applied to determine the stresses induced at blade mounting locations of a steam turbine rotor. The mechanical component as shown in the figure is the axisymmetric plane of a steam turbine rotor disc with radii at different sections as $a_{1}, a_{2}, a_{3}, a_{4}$ and $a_{5}$. The thicknesses at the corresponding sections are $b_{1}, b_{2}, b_{3}, b_{4}$ and $b_{5}$. The disc rotates with an angular velocity of $2600 \mathrm{rpm}$. The surface forces acting at radii $a_{1}, a_{2}, a_{4}$ and $a_{5}$ are considered as zero and the only surface force considered is at radii $a_{3}$. This force is the centrifugal force due to the rotation of the blade. Now using the equations derived above, the stresses as well as the radial displacement are determined.

To analyze this problem, first it is necessary to determine the stresses at radii $a_{1}, a_{2}, a_{3}$ and $a_{4}$ which are designated as $\sigma_{a l}, \sigma_{a 2}, \sigma_{a 3}$ and $\sigma_{a 4}$. Hence there are four unknown stresses which are to be determined. For this we use the compatibility equations of radial displacement, i.e. at each radius, the radial displacement of 
the outer edge of the inner zone is equal to the radial displacement of the inner edge of the outer zone. Again, the principle of superposition is used to determine the radial displacement at each interface.

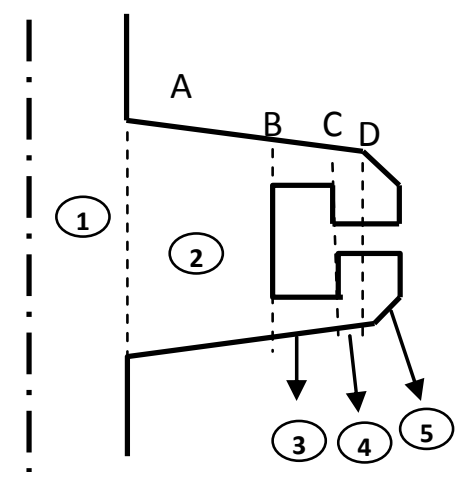

Fig.2. Blade mounting location of turbine rotor.

At interface $A$ of radius $a_{1}$, the radial displacement considering the interface $A$ on zone 1 is equated with the radial displacement considering the same interface $\mathrm{A}$ on zone 2 to determine a linear equation with unknowns $\sigma_{a 1}$ and $\sigma_{a 2}$. The radial displacement of interface A considering it on zone 1 is equal to the sum of two contributions determined at radius $a_{l}$, i.e. the radial displacement due to the centrifugal force of zone 1 and stress $\sigma_{a l}$.

The radial displacement of the same interface A considering it on zone 2 is equal to the sum of three contributions again determined at radius $\mathrm{a}_{1}$, i.e. the radial displacement due to the centrifugal force on zone2, stress $\sigma_{a 1}$ and stress $\sigma_{a 2}$.

At interface $\mathrm{B}$ of radius $\mathrm{a}_{2}$, the radial displacement considering the interface $\mathrm{B}$ on zone 2 is equated to the radial displacement considering the same interface $\mathrm{B}$ on zone 3 to determine the second linear equation with unknowns $\sigma_{a 2}$ and $\sigma_{a 3}$. The radial displacement of interface $\mathrm{B}$ considering it on zone 2 is equal to the sum of three contributions determined at radius $\mathrm{a}_{2}$, i.e. the radial displacement due to the centrifugal force of zone 2 and stress $\sigma_{a l}$ and stress $\sigma_{a 2}$. The radial displacement of the same interface B considering it on zone 3 is equal to the sum of three contributions again determined at radius $\mathrm{a}_{2}$, i.e. the radial displacement due to the centrifugal force on zone 3 , stress $\sigma_{a 2}$ and stress $\sigma_{a 3}$.

At interface $\mathrm{C}$ of radius $a_{3}$, the radial displacement considering the interface $\mathrm{C}$ on zone 3 is equated to the radial displacement considering the same interface $\mathrm{C}$ on zone 4 to determine the third linear equation with unknowns $\sigma_{a 3}$ and $\sigma_{a 4}$. The radial displacement of interface $\mathrm{C}$ considering it on zone 3 is equal to the sum of three contributions determined at radius $a_{3}$, i.e. the radial displacement due to the centrifugal force of zone 3 and stress $\sigma_{a 2}$ and stress $\sigma_{a 3}$. The radial displacement of the same interface $\mathrm{C}$ considering it on zone 4 is equal to the sum of three contributions again determined at radius $a_{3}$, i.e. the radial displacement due to the centrifugal force on zone 4 , stress $\sigma_{a 3}$ and stress $\sigma_{a 4}$.

At interface $\mathrm{D}$ of radius a4, the radial displacement considering the interface $\mathrm{D}$ on zone 4 is equated to the radial displacement considering the same interface $\mathrm{D}$ on zone 5 to determine the fourth linear equation with unknowns $\sigma_{a 4}$ and $\sigma_{a 5}$. The radial displacement of interface $\mathrm{D}$ considering it on zone 4 is equal to the sum of three contributions determined at radius $a_{4}$, i.e. the radial displacement due to the centrifugal force of zone 4 and stress $\sigma_{a 3}$ and stress $\sigma_{a 4}$. The radial displacement of the same interface D considering it on zone 5 is equal to the sum of two contributions again determined at radius $a_{4}$, i.e. the radial displacement due to the centrifugal force on zone 5 , stress $\sigma_{a 4}$.

The four linear equations are solved and the stresses $\sigma_{a l}, \sigma_{a 2}, \sigma_{a 3}$ and $\sigma_{a 4}$ at the interfaces $\mathrm{A}, \mathrm{B}, \mathrm{C}$ and $\mathrm{D}$ are determined.

\section{Results}

Using the analytical equations derived for a rotating disc and applying these equations for a steam turbine rotor disc, the tangential stress, radial stress and radial displacement are determined along the radius. 
The variations of theses parameters with respect to the radius from the axis of rotation are plotted. The variation of radial stresses with respect to the radius is given in Tabs 1-5 and plot is shown in Figs 3-7. The tangential stresses developed are determined and the variation of these stresses is presented in Tabs 6-10 and Figs 9-13. The variation of radial stress, tangential stress and radial displacement against the entire radius is shown in Fig.8 and Figs 14-15.

Table 1. Variation of radial stress in zone 1.

\begin{tabular}{lcc}
\hline & \multicolumn{2}{c}{ Radial Stress $\left(M N / m^{2}\right)$} \\
\cline { 2 - 3 } Radius $(m)$ & $\begin{array}{c}\text { without } \\
\text { centrifugal force }\end{array}$ & $\begin{array}{c}\text { with } \\
\text { centrifugal force }\end{array}$ \\
\hline 0.000 & 44.46 & 47.41 \\
0.040 & 47.75 & 50.7 \\
0.081 & 49.76 & 52.71 \\
0.121 & 49.03 & 51.98 \\
0.161 & 46.11 & 49.06 \\
0.202 & 42.27 & 45.21 \\
0.242 & 37.14 & 40.09 \\
\hline
\end{tabular}

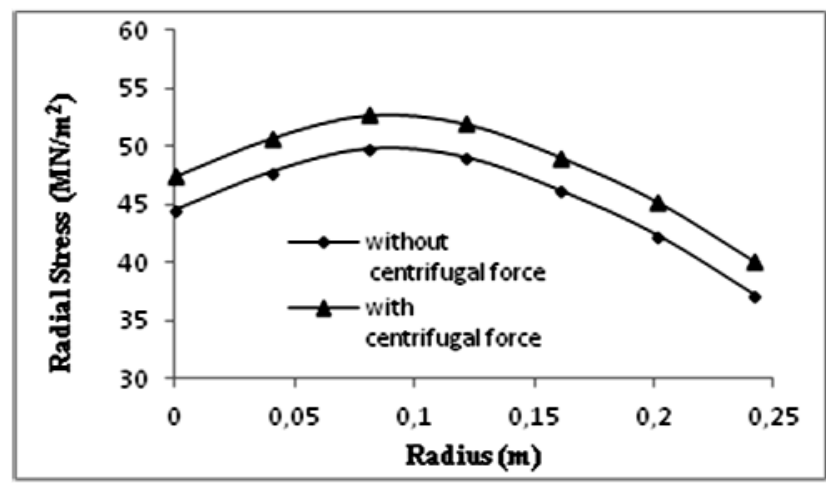

Fig.3. Variation of radial stress in zone 1.

Table 2. Variation of radial stress in zone 2.

\begin{tabular}{lcc}
\hline & \multicolumn{2}{c}{ Radial Stress $\left(M N / \mathrm{m}^{2}\right)$} \\
\cline { 2 - 3 } Radius $(m)$ & $\begin{array}{c}\text { without } \\
\text { centrifugal force }\end{array}$ & $\begin{array}{c}\text { with } \\
\text { centrifugal force }\end{array}$ \\
\hline 0.242 & 56.43 & 57.82 \\
0.284 & 62.1 & 63.28 \\
0.325 & 58.32 & 59.64 \\
0.367 & 52.65 & 54.19 \\
0.409 & 45.08 & 46.91 \\
0.450 & 34.69 & 36.91 \\
0.492 & 18.62 & 21.46 \\
\hline
\end{tabular}

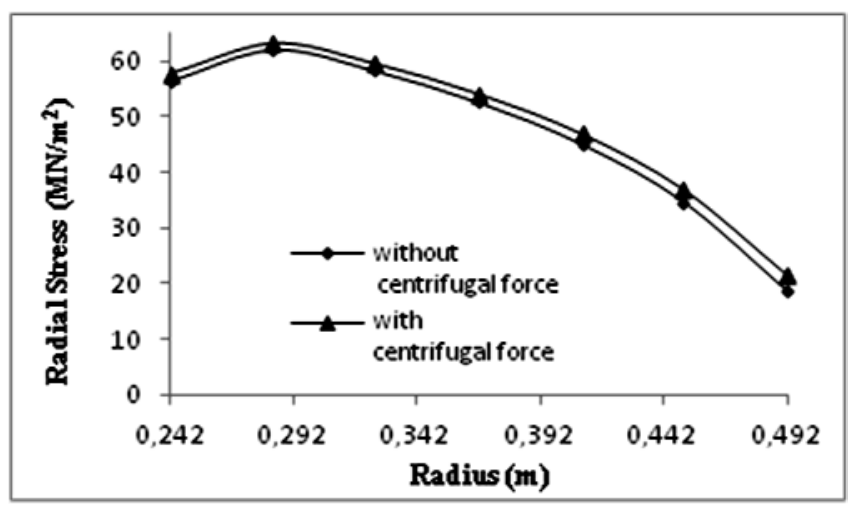

Fig.4. Variation of radial stress in zone 2.

Table 3. Variation of radial stress in zone 3.

\begin{tabular}{lcc|}
\hline \multirow{2}{*}{ Radius $(m)$} & \multicolumn{2}{c}{ Radial Stress $\left(M N / \mathrm{m}^{2}\right)$} \\
\cline { 2 - 3 } & $\begin{array}{c}\text { without } \\
\text { centrifugal force }\end{array}$ & $\begin{array}{c}\text { with } \\
\text { centrifugal force }\end{array}$ \\
\hline 0.492 & 23.19 & 29.33 \\
0.495 & 30.42 & 33.86 \\
0.499 & 34.84 & 36.62 \\
0.502 & 33.23 & 35.62 \\
0.505 & 26.8 & 31.59 \\
0.509 & 18.36 & 26.3 \\
0.512 & 7.12 & 19.26 \\
\hline
\end{tabular}

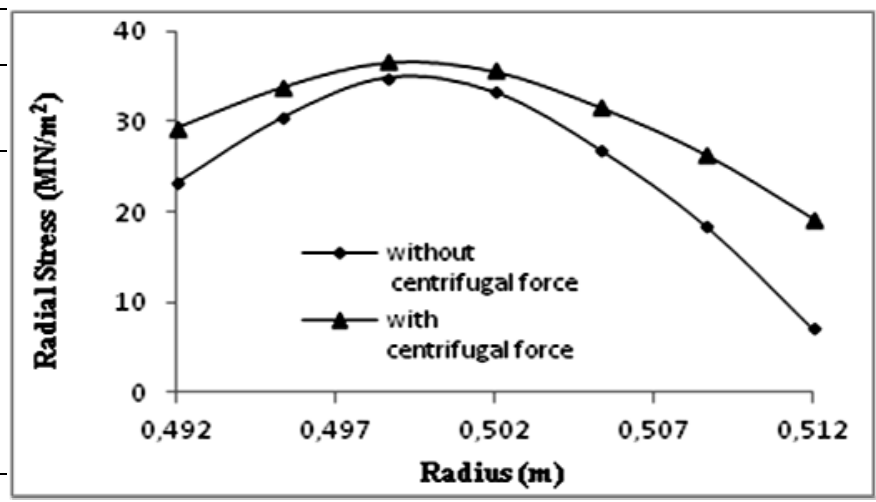

Fig.5. Variation of radial stress in zone 3. 
Table 4. Variation of radial stress in zone 4.

\begin{tabular}{lcc}
\hline & \multicolumn{2}{c}{ Radial Stress $\left(M N / \mathrm{m}^{2}\right)$} \\
\cline { 2 - 3 } Radius $(m)$ & $\begin{array}{c}\text { without } \\
\text { centrifugal force }\end{array}$ & $\begin{array}{c}\text { with } \\
\text { centrifugal force }\end{array}$ \\
\hline 0.512 & 9.26 & 57.26 \\
0.513 & 11.38 & 72.93 \\
0.515 & 12.69 & 82.52 \\
0.516 & 12.21 & 79.03 \\
0.517 & 10.32 & 65.1 \\
0.519 & 7.84 & 46.8 \\
0.520 & 4.53 & 22.41 \\
\hline
\end{tabular}

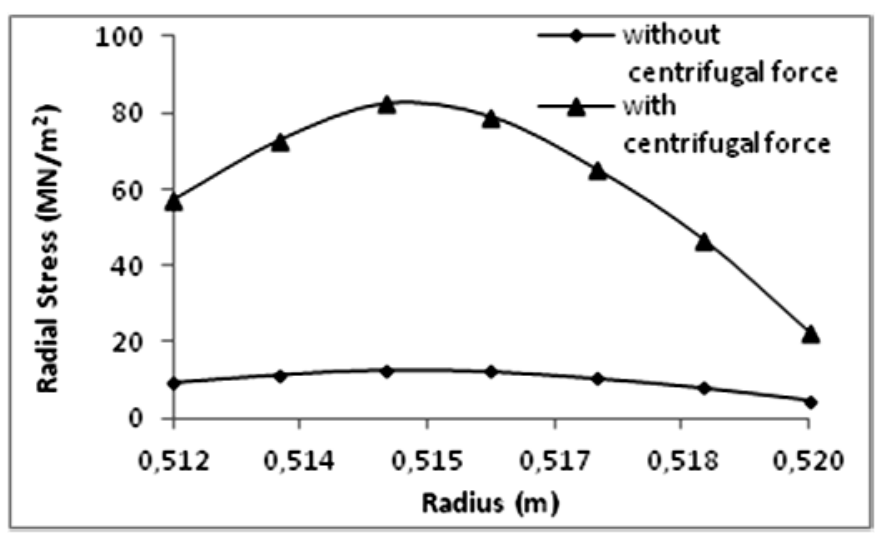

Fig.6. Variation of radial stress in zone 4.

Table 5. Variation of radial stress in zone 5.

\begin{tabular}{lcc}
\hline \multirow{2}{*}{ Radius $(m)$} & \multicolumn{2}{c}{ Radial Stress $\left(M N / m^{2}\right)$} \\
\cline { 2 - 3 } & $\begin{array}{c}\text { without } \\
\text { centrifugal force }\end{array}$ & $\begin{array}{c}\text { with } \\
\text { centrifugal force }\end{array}$ \\
\hline 0.520 & 5.63 & 17.33 \\
0.523 & 8.16 & 25.12 \\
0.526 & 9.7 & 29.89 \\
0.529 & 9.14 & 28.15 \\
0.531 & 6.89 & 21.22 \\
0.534 & 3.94 & 12.13 \\
0.537 & 0 & 0 \\
\hline
\end{tabular}

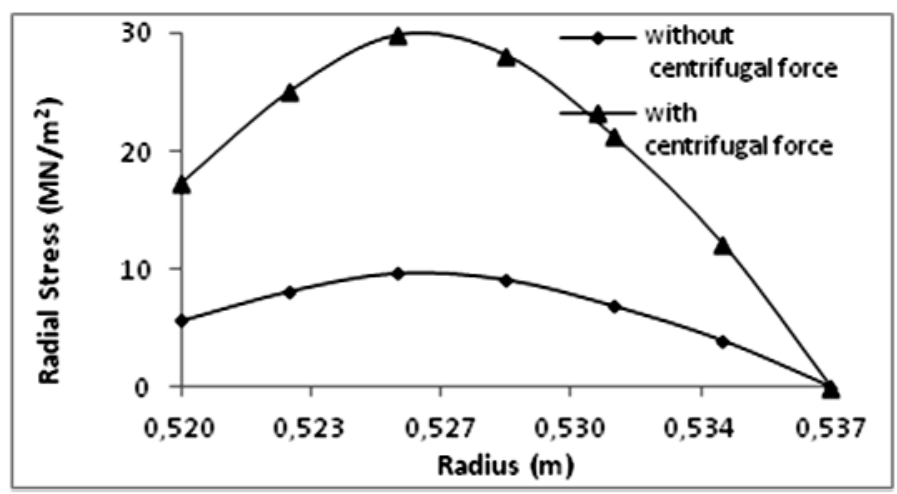

Fig.7. Variation of radial stress in zone 5.

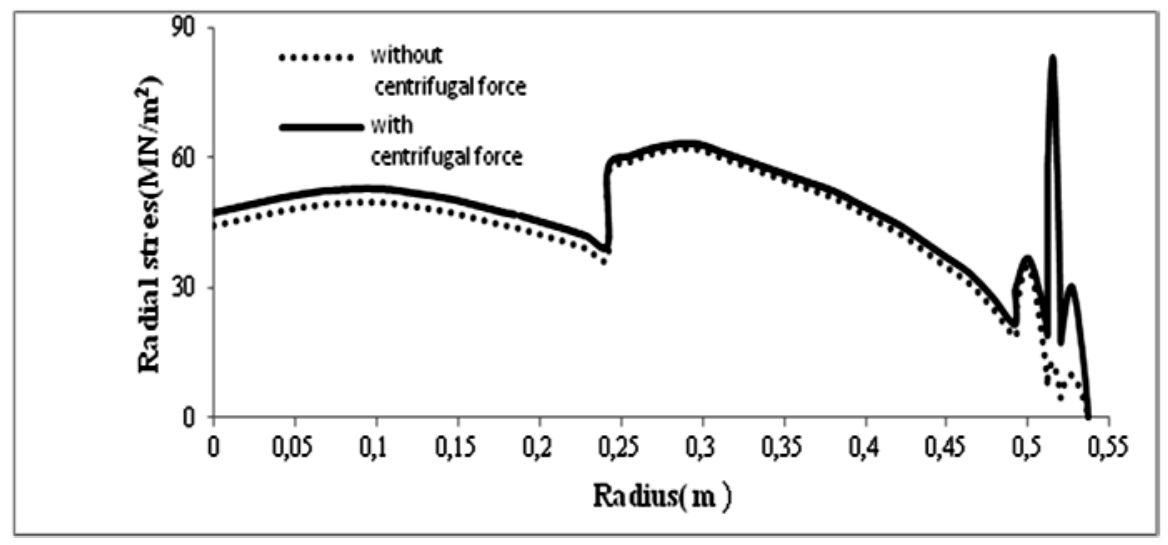

Fig.8. Variation of radial stress in all the zones. 
Table 6. Variation of tangential stress in zone 1.

\begin{tabular}{lcc}
\hline \multirow{2}{*}{ Radius $(m)$} & \multicolumn{2}{c}{ Tangential Stress $\left(\mathrm{MN} / \mathrm{m}^{2}\right)$} \\
\cline { 2 - 3 } & $\begin{array}{c}\text { without } \\
\text { centrifugal force }\end{array}$ & $\begin{array}{c}\text { with } \\
\text { centrifugal force }\end{array}$ \\
\hline 0.000 & 44.48 & 47.49 \\
0.040 & 44.12 & 47.12 \\
0.081 & 43.06 & 46.03 \\
0.121 & 41.68 & 44.62 \\
0.161 & 40.88 & 43.8 \\
0.202 & 40.48 & 43.39 \\
0.242 & 40.26 & 43.16 \\
\hline
\end{tabular}

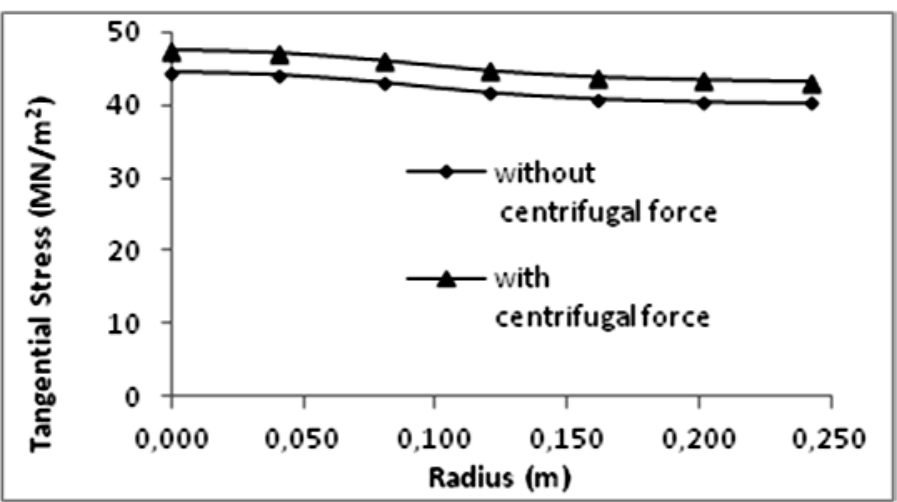

Fig.9. Variation of tangential stress in zone 1.

Table 7. Variation of tangential stress in zone 2.

\begin{tabular}{lcc}
\hline \multirow{2}{*}{ Radius $(m)$} & \multicolumn{2}{c}{ Tangential Stress $\left(M N / \mathrm{m}^{2}\right)$} \\
\cline { 2 - 3 } & $\begin{array}{c}\text { without } \\
\text { centrifugal force }\end{array}$ & $\begin{array}{c}\text { with } \\
\text { centrifugal force }\end{array}$ \\
\hline 0.242 & 42.88 & 48.58 \\
0.284 & 40.91 & 46.53 \\
0.325 & 35 & 40.38 \\
0.367 & 27.36 & 32.44 \\
0.409 & 22.93 & 27.83 \\
0.450 & 20.71 & 25.53 \\
0.492 & 19.48 & 24.25 \\
\hline
\end{tabular}

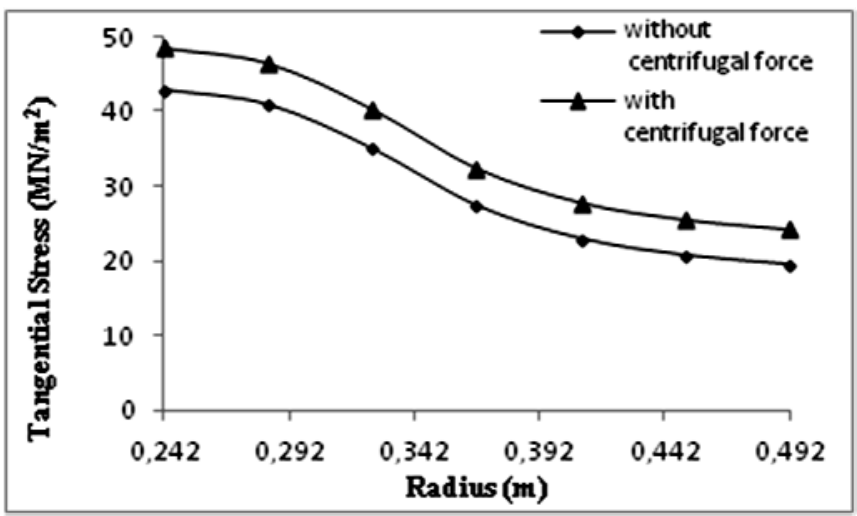

Fig.10. Variation of tangential stress in zone 2.

Table 8. Variation of tangential stress in zone 3.

\begin{tabular}{lcc}
\hline & \multicolumn{2}{c}{ Tangential Stress $\left(M N / m^{2}\right)$} \\
\cline { 2 - 3 } Radius $(m)$ & $\begin{array}{c}\text { without } \\
\text { centrifugal force }\end{array}$ & $\begin{array}{c}\text { with } \\
\text { centrifugal force }\end{array}$ \\
\hline 0.492 & 23.55 & 34.76 \\
0.495 & 23.35 & 33.87 \\
0.499 & 22.76 & 31.21 \\
0.502 & 22.01 & 27.77 \\
0.505 & 21.57 & 25.77 \\
0.509 & 21.35 & 24.77 \\
0.512 & 21.23 & 24.22 \\
\hline
\end{tabular}

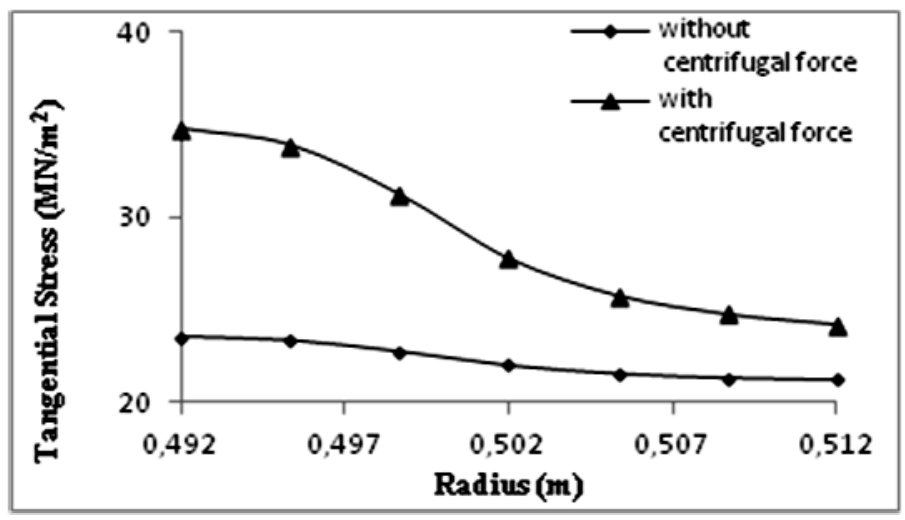

Fig.11. Variation of tangential stress in zone 3. 
Table 9. Variation of tangential stress in zone 4.

\begin{tabular}{lcc}
\hline & \multicolumn{2}{c}{ Tangential Stress $\left(M N / \mathrm{m}^{2}\right)$} \\
\cline { 2 - 3 } Radius $(m)$ & $\begin{array}{c}\text { without } \\
\text { centrifugal force }\end{array}$ & $\begin{array}{c}\text { with } \\
\text { centrifugal force }\end{array}$ \\
\hline 0.512 & 23.38 & 24.96 \\
0.513 & 23.04 & 24.87 \\
0.515 & 22.03 & 24.62 \\
0.516 & 20.71 & 24.29 \\
0.517 & 19.95 & 24.1 \\
0.519 & 19.57 & 24.1 \\
0.520 & 19.36 & 23.95 \\
\hline
\end{tabular}

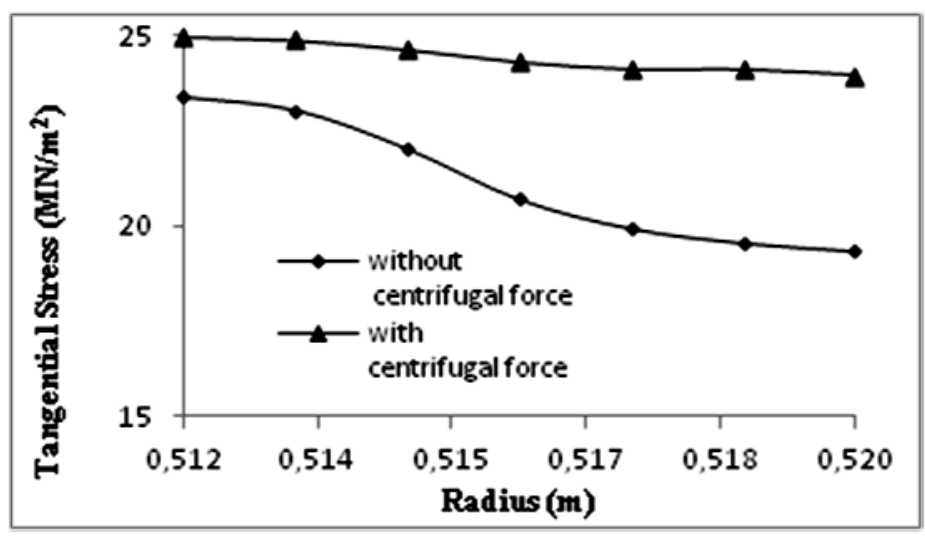

Fig.12 Variation of tangential stress in zone 4.

Table 10. Variation of tangential stress in zone 5.

\begin{tabular}{lcc}
\hline & \multicolumn{2}{c}{ Tangential Stress $\left(M N / \mathrm{m}^{2}\right)$} \\
\cline { 2 - 3 } Radius $(m)$ & $\begin{array}{c}\text { without } \\
\text { centrifugal force }\end{array}$ & $\begin{array}{c}\text { with } \\
\text { centrifugal force }\end{array}$ \\
\hline 0.520 & 36.82 & 38.48 \\
0.523 & 36.51 & 38.15 \\
0.526 & 35.57 & 37.16 \\
0.529 & 34.36 & 35.89 \\
0.531 & 33.65 & 35.15 \\
0.534 & 33.3 & 34.79 \\
0.537 & 33.11 & 34.59 \\
\hline
\end{tabular}

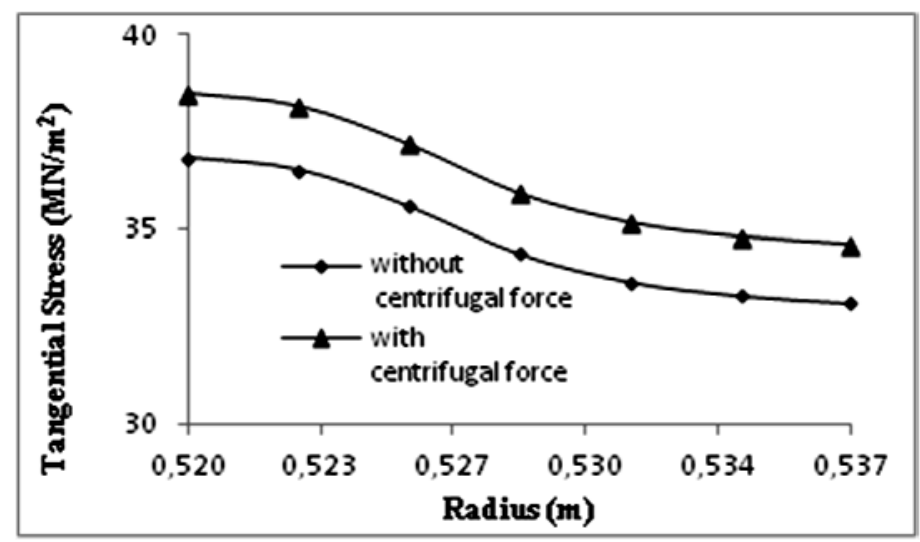

Fig.13. Variation of tangential stress in zone 5.

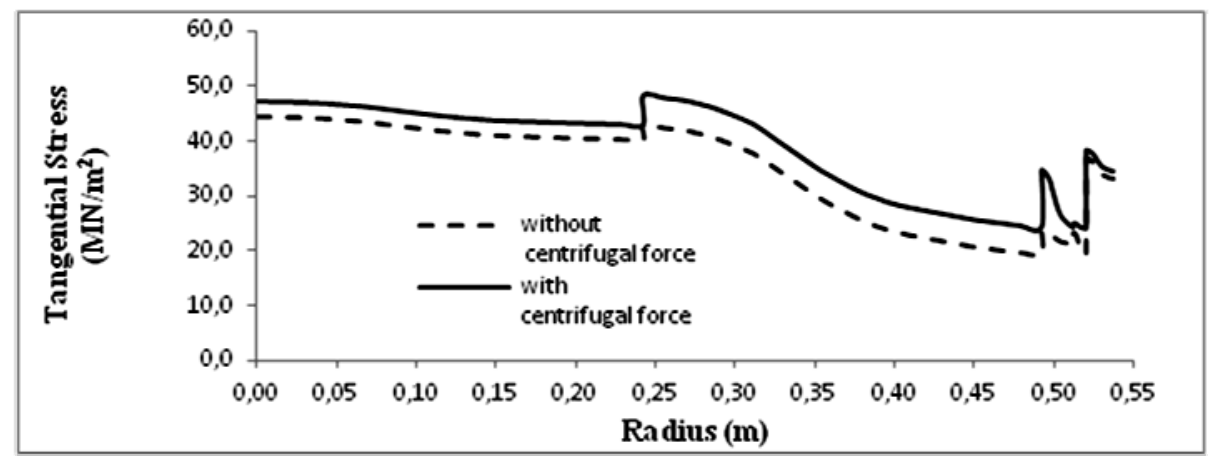

Fig.14. Variation of tangential stress in all the zones. 


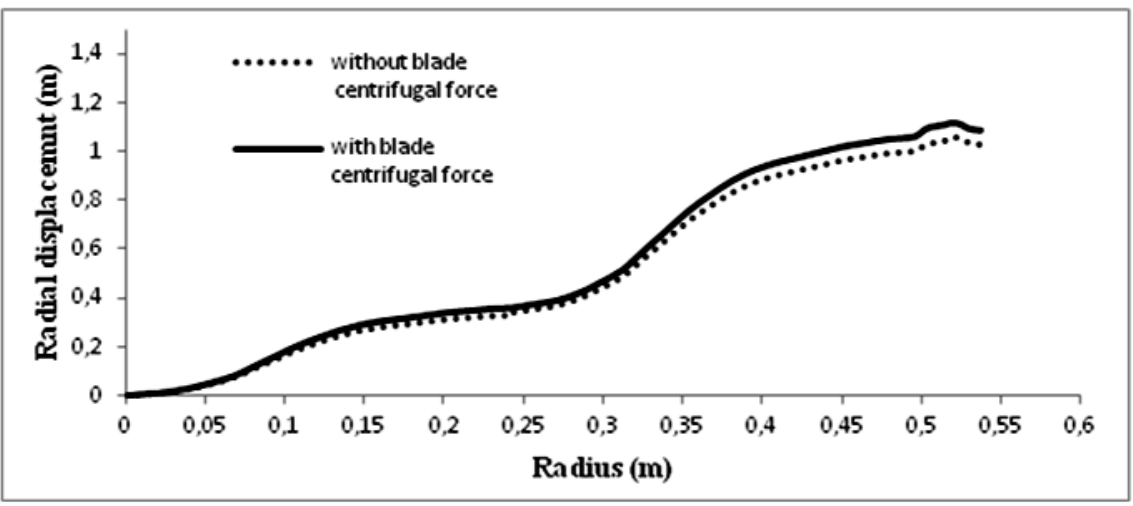

Fig.15. Variation of radial displacement in all the zones.

\section{Determination of stresses and displacement using Ansys}

The stresses induced at blade mounting locations in the turbine rotor are also determined by solving the problem using Ansys package. The problem is considered an axi symmetric problem and the finite element model is shown in Fig.16. PLANE183 element is used in the analysis and the meshed model is shown in Fig.17. Path operations are used to plot the variations of radial stress, tangential stress and radial displacement as shown in Figs 18-23. The results obtained using mathematical model are compared with these results and the error is shown in Tab.11.

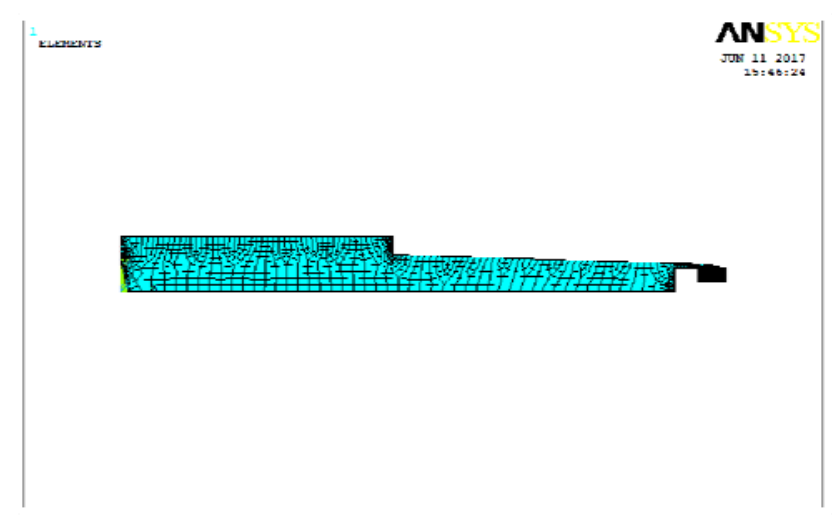

Fig.16. Finite element model of steam turbine rotor.

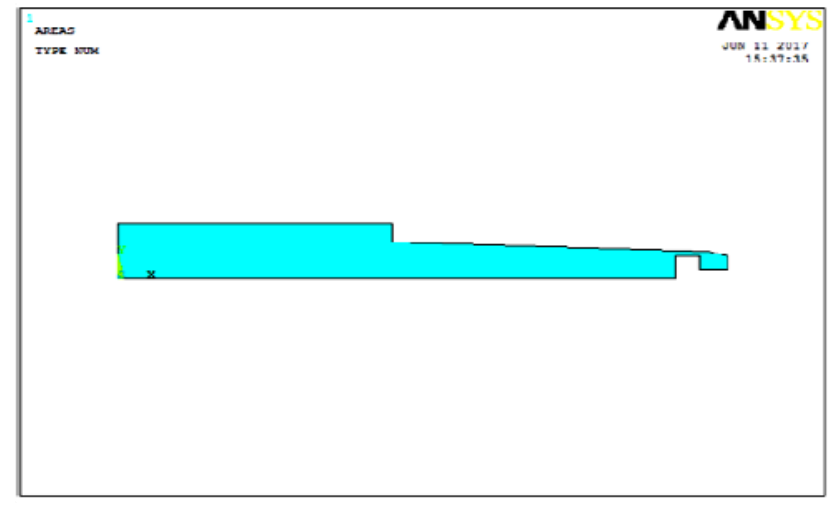

Fig.17. Meshed model of steam turbine rotor. 


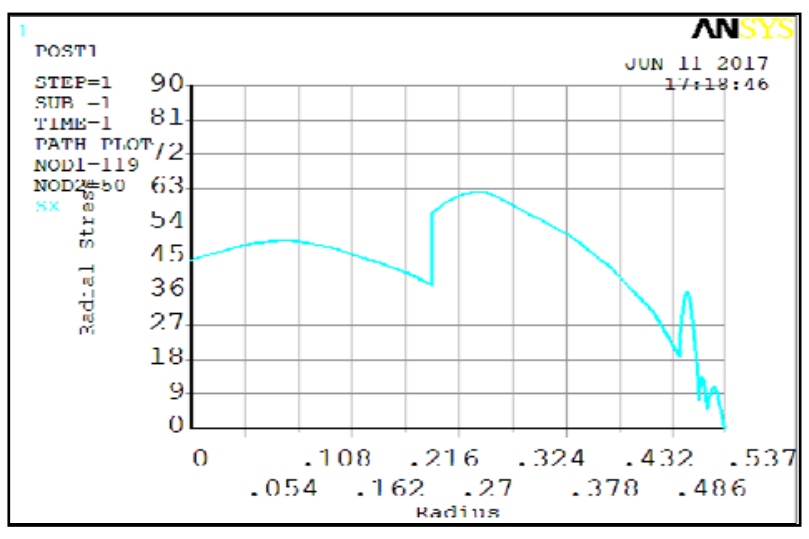

Fig.18. Variation of radial stress (without centrifugal force).

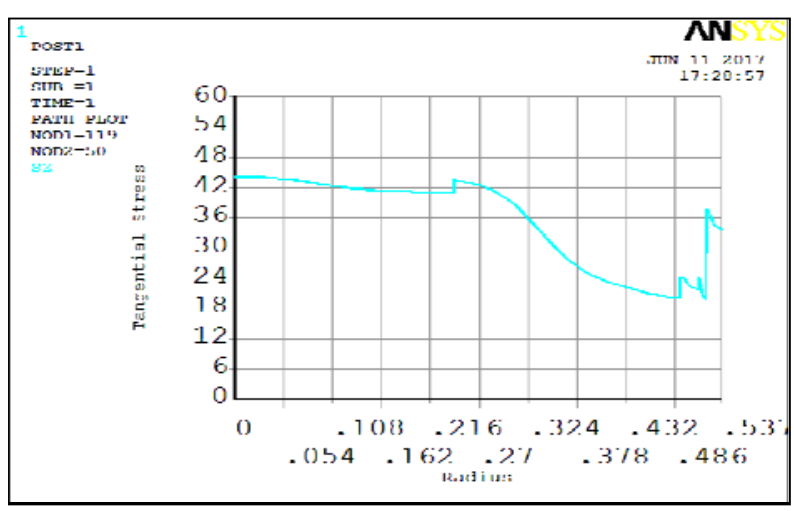

Fig.20. Variation of tangential stress (without centrifugal force).

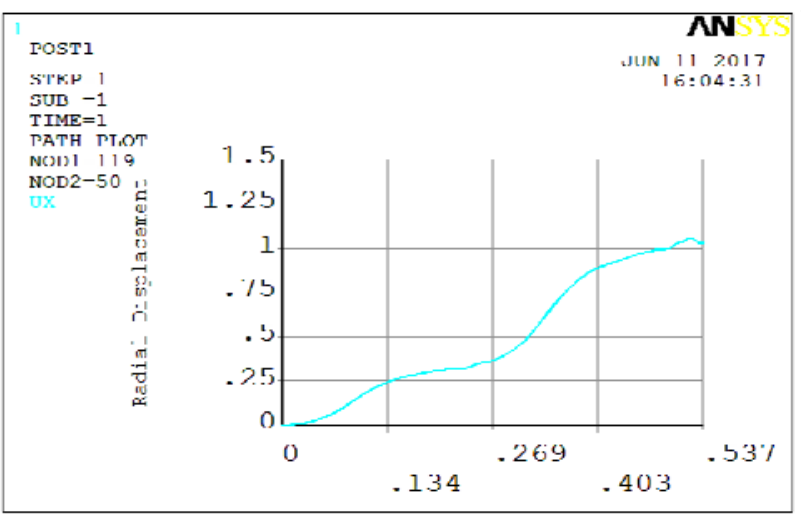

Fig.22. Variation of radial displacement (without centrifugal force).

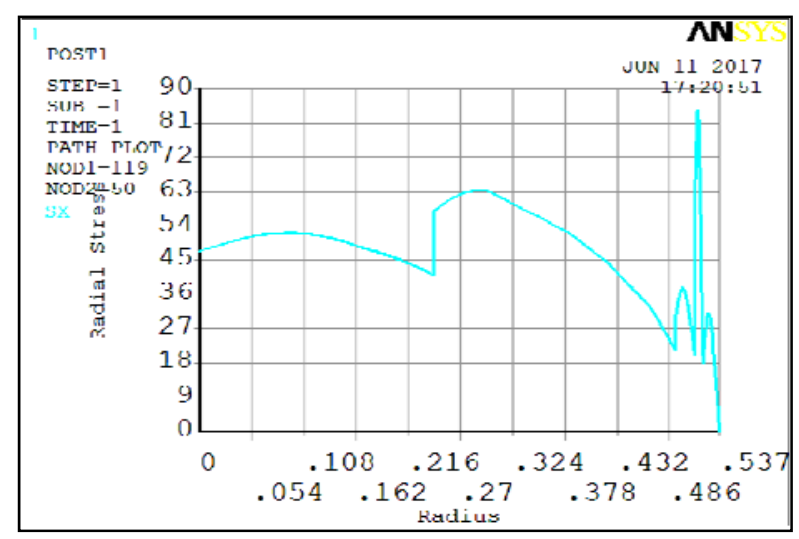

Fig.19. Variation of radial stress (with centrifugal force).

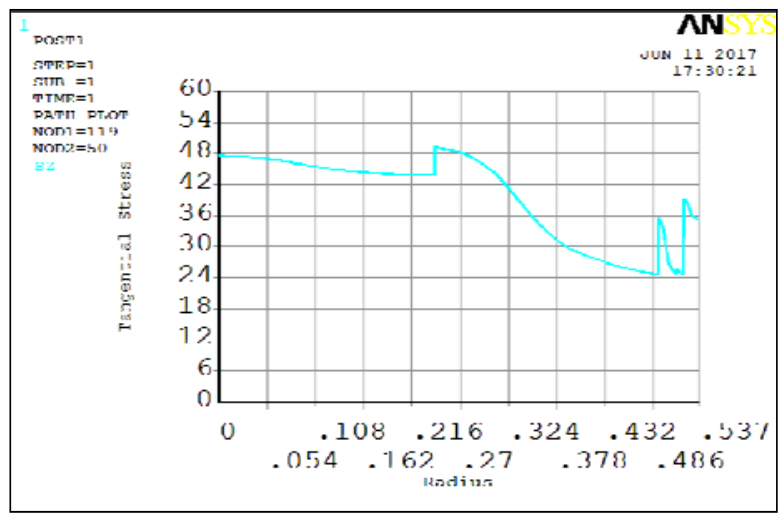

Fig.21. Variation of tangential stress (with centrifugal force).

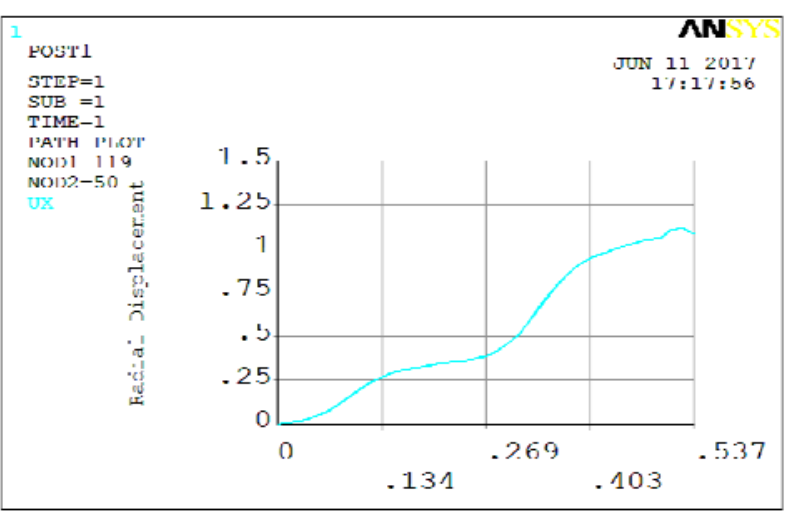

Fig.23. Variation of radial displacement (with centrifugal force). 
Table 11. Comparison of radial and tangential stresses obtained using mathematical model and Ansys.

\begin{tabular}{|c|c|c|c|c|c|c|c|c|c|c|c|c|c|}
\hline \multirow{2}{*}{ Zone } & \multirow{2}{*}{$\begin{array}{l}\text { Radius } \\
(m)\end{array}$} & \multicolumn{3}{|c|}{$\begin{array}{l}\text { Radial Stress }-M N / m^{2} \\
\text { (without centrifugal force) }\end{array}$} & \multicolumn{3}{|c|}{$\begin{array}{l}\text { Radial Stress }-M N / m^{2} \\
\text { (with centrifugal force) }\end{array}$} & \multicolumn{3}{|c|}{$\begin{array}{l}\text { Tangential Stress }-M N / m^{2} \\
\text { (without centrifugal force) }\end{array}$} & \multicolumn{3}{|c|}{$\begin{array}{l}\text { Tangential Stress- } M N / m^{2} \\
\text { (with centrifugal force) }\end{array}$} \\
\hline & & $\begin{array}{l}\text { Mathematical } \\
\text { model }\end{array}$ & Ansys & $\begin{array}{c}\text { Error } \\
(\%)\end{array}$ & $\begin{array}{l}\text { Mathematical } \\
\text { model }\end{array}$ & Ansys & $\begin{array}{c}\text { Error } \\
(\%)\end{array}$ & $\begin{array}{c}\text { Mathematical } \\
\text { model }\end{array}$ & Ansys & $\begin{array}{c}\text { Error } \\
(\%)\end{array}$ & $\begin{array}{l}\text { Mathematical } \\
\text { model }\end{array}$ & Ansys & $\begin{array}{c}\text { Error } \\
(\%)\end{array}$ \\
\hline \multirow{7}{*}{1} & 0 & 44.46 & 44.26 & 0.46 & 47.41 & 47.51 & -0.22 & 44.48 & 44.26 & 0.50 & 47.49 & 47.53 & -0.07 \\
\hline & 0.04 & 47.75 & 47.24 & 1.07 & 50.7 & 50.39 & 0.62 & 44.12 & 43.98 & 0.32 & 47.12 & 47.21 & -0.20 \\
\hline & 0.081 & 49.76 & 49.06 & 1.40 & 52.71 & 52.14 & 1.08 & 43.06 & 43.15 & -0.20 & 46.03 & 46.28 & -0.54 \\
\hline & 0.121 & 49.03 & 48.4 & 1.28 & 51.98 & 51.5 & 0.92 & 41.68 & 42.07 & -0.93 & 44.62 & 45.07 & -1.01 \\
\hline & 0.161 & 46.11 & 45.75 & 0.78 & 49.06 & 48.95 & 0.23 & 40.88 & 41.44 & -1.38 & 43.8 & 44.37 & -1.30 \\
\hline & 0.202 & 42.27 & 42.27 & 0.01 & 45.21 & 45.6 & -0.85 & 40.48 & 41.13 & -1.61 & 43.39 & 44.02 & -1.45 \\
\hline & 0.242 & 37.14 & 37.63 & -1.31 & 40.09 & 41.13 & -2.58 & 40.26 & 40.96 & -1.73 & 43.16 & 43.83 & -1.54 \\
\hline \multirow{7}{*}{2} & 0.242 & 56.43 & 56.72 & -0.51 & 57.82 & 58.01 & -0.33 & & 43.58 & -1.63 & & 49.26 & -1.40 \\
\hline & 0.284 & 62.1 & 62.94 & -1.35 & 63.28 & 63.73 & -0.70 & 40.91 & 41.6 & -1.68 & 46.53 & 47.19 & -1.42 \\
\hline & 0.325 & 58.32 & 58.76 & -0.75 & 59.64 & 60.37 & -1.22 & & 65 & -1.84 & & 41.1 & -1.52 \\
\hline & 0.367 & 52.65 & 52.98 & -0.63 & 54.19 & 54.52 & -0.61 & 27.36 & 27.96 & -2.19 & 32.44 & 32.99 & -1.69 \\
\hline & 0.409 & 45.08 & 45.46 & -0.84 & 46.91 & 47.65 & -1.58 & & 23.5 & -2.47 & & 28.34 & -1.84 \\
\hline & 0.45 & 34.69 & 35.02 & -0.95 & 36.91 & 37.31 & -1.08 & 20.71 & 21.27 & -2.68 & 53 & 26.02 & -1.91 \\
\hline & 0.492 & 18.62 & 18.95 & -1.77 & 21.46 & 21.83 & -1.70 & & 20.03 & -2.80 & & 24.73 & -1.96 \\
\hline \multirow{7}{*}{3} & 0.492 & 23.19 & 23.65 & -1.97 & 29.33 & 30.15 & -2.78 & & 24.18 & -2.67 & 76 & 35.43 & -1.92 \\
\hline & 0.495 & 30.42 & 30.98 & -1.84 & 33.86 & 34.69 & -2.45 & & 23.98 & -2.71 & & .54 & -1.97 \\
\hline & 0.499 & 34.84 & 35.46 & -1.79 & 36.62 & & -2.31 & & 3.4 & -2.80 & & 31.87 & -2.10 \\
\hline & 0.502 & 33.23 & 33.83 & -1.82 & 35.62 & 36.46 & -2.35 & 22.01 & 22.64 & -2.86 & 77 & 28.42 & -2.33 \\
\hline & 0.505 & & & -1.92 & & & -2.62 & & & -2.92 & & 42 & -2.51 \\
\hline & 0.509 & 18.36 & 18.76 & -2.16 & 26.3 & 27.12 & -3.11 & & 21.98 & -2.96 & 77 & 25.42 & -2.60 \\
\hline & 0.512 & & 7.35 & -3.17 & & & -4.10 & & & -2.96 & & 86 & -2.64 \\
\hline \multirow{7}{*}{4} & 0.512 & 9.26 & 9.51 & -2.70 & 57.26 & 58.13 & -1.51 & & 23.96 & -2.48 & 96 & .75 & -3.16 \\
\hline & 0.513 & 11.38 & 11.72 & -2.99 & 72.93 & & -1.53 & & 23.62 & -2.53 & 24.87 & 66 & -3.17 \\
\hline & 0.515 & 12.69 & 13.08 & -3.07 & 82.52 & 83.78 & -1.53 & 22.03 & 22.61 & -2.64 & 24.62 & 25.39 & -3.12 \\
\hline & 0.516 & 12.21 & 12.51 & -2.46 & 79.03 & 80.24 & -1.53 & 20.71 & 21.31 & -2.88 & 24.29 & 25.04 & -3.08 \\
\hline & 0.517 & 10.32 & 10.59 & -2.62 & & 66.09 & -1.52 & & 20.55 & -3.00 & 24.1 & 24.84 & -3.05 \\
\hline & 0.519 & 7.84 & 8.08 & -3.06 & 46.8 & 47.51 & -1.52 & 19.57 & 20.17 & -3.06 & 24.1 & 24.73 & -3.06 \\
\hline & & & 4.62 & -1.99 & 22.41 & 22.75 & -1.50 & & 19.96 & -3.09 & 23.95 & 24.68 & -3.04 \\
\hline \multirow{7}{*}{5} & 0.52 & 5.63 & 5.82 & -3.37 & 17.33 & 17.83 & -2.86 & 36.82 & 37.65 & -2.24 & 38.48 & 39.17 & -1.80 \\
\hline & 0.523 & 8.16 & 8.29 & -1.59 & 25.12 & 25.85 & -2.89 & & 37.33 & -2.23 & 38.15 & 38.84 & -1.82 \\
\hline & 0.526 & 9.7 & 9.91 & -2.16 & 29.89 & 30.75 & -2.87 & 35.57 & 36.37 & -2.24 & 37.16 & 37.85 & -1.86 \\
\hline & 0.529 & 9.14 & 9.33 & -2.08 & 28.15 & 28.97 & -2.90 & 34.36 & 35.13 & -2.23 & 35.89 & 36.57 & -1.89 \\
\hline & 0.531 & 6.89 & 7.01 & -1.74 & 21.22 & 21.84 & -2.90 & 33.65 & 34.41 & -2.25 & 35.15 & 35.82 & -1.92 \\
\hline & 0.534 & 3.94 & 4.05 & -2.79 & 12.13 & 12.48 & -2.87 & & 34.05 & -2.25 & 34.79 & 35.45 & -1.90 \\
\hline & 0.537 & 0 & 0 & 0.00 & 0 & 0 & 0.00 & 33.11 & 33.85 & -2.23 & 34.59 & 35.25 & -1.90 \\
\hline
\end{tabular}

\section{Conclusions}

The analytical solution of the general differential equation for a rotating disk of varying thickness subjected to a non-zero thermal load with the displacement as primary variable is derived. By applying different boundary conditions, the unknown constants in the solution are determined and general equations for the radial stress, tangential stress and radial displacement are derived. These equations are applied to analyze the stresses induced and radial displacement in a steam turbine rotor disc. The variations of radial stress, tangential stress and radial displacement are plotted and the following conclusions are made. It is observed that the centrifugal force because of the rotation of blades increases the radial and tangential stresses along the entire radius. Especially at the junction between zones 3 and 4 where the centrifugal force is considered, there is a sudden increase in the radial stress which signals the initiation of crack at this 
junction. The variation of radial displacement indicates that the maximum displacement occurs at the junction between zones 4 and 5 . The results obtained using the mathematical model approach is validated with Ansys results and the error is less than $4 \%$.

\section{Nomenclature}

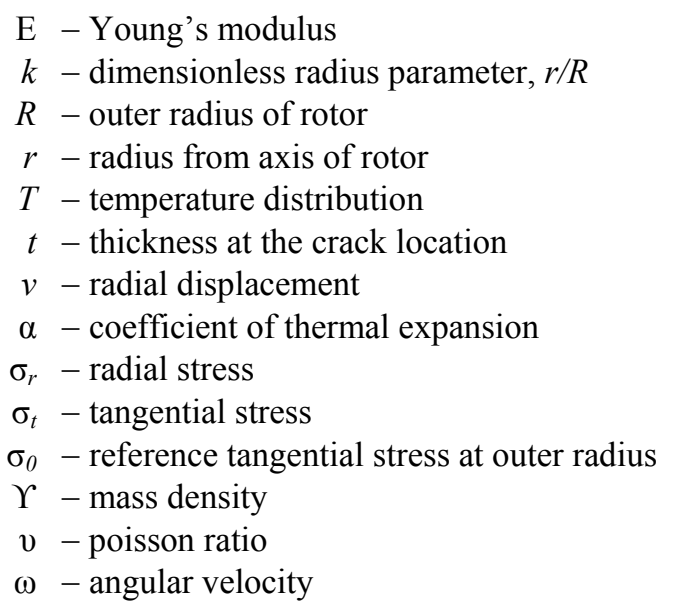

\section{References}

[1] Naumann H.G. (1982): Steam turbine blade design options: how to specify or upgrade. - Proceedings Of The Eleventh Turbomachinery Symposium, pp.29-49.

[2] Fernando Rueda Martínez, Juan Abugaber Francis, M. Toledo-Velázquez and Ignacio Carvajal (2011): Theoretical and numerical analysis of the mechanical erosion in steam turbine blades. - Energy and Power Engineering, pp.227-237.

[3] Mazur Z., Garcia-Illescas R., Agurirre-Romano J. and Perez Rodriguez N. (2008): Steam turbine blade failure analysis. - Engineering Failure Analysis, vol.15, pp.129-141.

[4] Shankar M., Kumar K. and Ajit Prasad S.L. (2010): T-root blades in a steam turbine rotor: a case study. Engineering Failure Analysis, vol.17, pp.1205-1212.

[5] Plesiutschnig E. (2016): Fracture analysis of a low pressure steam turbine blade. - Engineering Failure Analysis, pp.39-50.

[6] Vivio F. (2014): Theoretical stress analysis of rotating hyperbolic disk without singularities subjected to thermal load. - Journal of Thermal Stresses, vol.37, pp.117-136.

[7] Vasovic I. (2014): Determination of Stress Intensity Factors in Low Pressure Turbine Rotor Discs. - Mathematical Problems In Engineering, vol.4.

[8] Rao J.S. (2004): Transient stress analysis and fatigue life estimation of turbine blades. - Journal of Vibration Accoustics, ASME, vol.126, pp.485-495. 